\title{
Health-related quality of life (HRQoL) in a population at risk of type 2 diabetes: a cross-sectional study in two Latin American cities
}

\author{
Luis A. Anillo Arrieta ${ }^{1,2^{*}}$ (1), Tania Acosta Vergara ${ }^{2}$, Rafael Tuesca ${ }^{2,3}$, Sandra Rodríguez Acosta ${ }^{4}$, \\ Karen C. Flórez Lozano', Pablo Aschner ${ }^{5,6,7}$, Rafael Gabriel ${ }^{8,9}$, Sandra De La Rosa², Julieth P. Nieto Castillo ${ }^{2}$ and \\ Noël C. Barengo ${ }^{10,11,12}$
}

\begin{abstract}
Purpose: The purpose of this study was to describe the health-related quality of life (HRQOL) characteristics in a population at risk of developing type 2 diabetes in Barranquilla and Bogotá, Colombia.

Methods: A cross-sectional study with 1135 participants older than 30 years-of-age recruited in Bogotá D.C., and Barranquilla by cluster sampling in 2018 to 2019. The Finnish Diabetes Risk Score (FINDRISC) was used to detect participants at risk of developing type 2 diabetes (T2D). HRQoL was assessed using the EQ-5D-3L questionnaire. Unadjusted and adjusted logistic regression models were used to calculate odds ratios (OR) and their corresponding 95\% confidence intervals (I).
\end{abstract}

Results: Moderate or extreme problems appeared more frequently in the dimensions of Pain/Discomfort (60.8\%) and Anxiety/Depression (30.8\%). The mean score of the EQ-VAS was 74.3 ( \pm 17.3 ), significantly larger in the state of complete health (11111) compared with those with problems in more than one of the quality-of-life dimensions. Being female and living in Bogota D.C., were associated with greater odds of reporting problems in the Pain (OR 1.6; 95\% Cl 1.2-2.2) and Discomfort dimensions (OR 1.6; 95\% Cl 1.2-2.0) respectively and Anxiety/Depression (OR 1.9; 95\% Cl 1.3-2.7), (OR 9.1; 95\% Cl 6.6-12.4), respectively.

Conclusions: As living place and sex were associated with dimensions of Pain/Discomfort and Anxiety/Depression in the HRQoL in people at risk of T2D, greater attention should be paid to these determinants of HRQoL to design and reorient strategies with a territorial and gender perspective to achieve better health outcomes.

Plain English summary: Diabetes is one of the four non-communicable diseases with increasing prevalence in the world, which has made it a serious public health problem. In Colombia, in 2019 diabetes affected 8.4\% of the Colombian adult population and more than one million Colombian adults of this age group have hidden or undetected diabetes. This disease is not only characterized by increased premature mortality, loss of productivity, and economic impact, but it also involves a deterioration in the quality of life of people with diabetes with their respective families. However, very Little is known about health-related quality of life (HRQoL) in a population at risk or with prediabetes.

*Correspondence: laanillo@uninorte.edu.co

1 Department of Mathematics and Statistics, Division of Basic Sciences,

Universidad del Norte, Barranquilla, Colombia

Full list of author information is available at the end of the article

(c) The Author(s) 2021. Open Access This article is licensed under a Creative Commons Attribution 4.0 International License, which permits use, sharing, adaptation, distribution and reproduction in any medium or format, as long as you give appropriate credit to the original author(s) and the source, provide a link to the Creative Commons licence, and indicate if changes were made. The images or other third party material in this article are included in the article's Creative Commons licence, unless indicated otherwise in a credit line to the material. If material is not included in the article's Creative Commons licence and your intended use is not permitted by statutory regulation or exceeds the permitted use, you will need to obtain permission directly from the copyright holder. To view a copy of this licence, visit http://creativecommons.org/licenses/by/4.0/. The Creative Commons Public Domain Dedication waiver (http://creativeco mmons.org/publicdomain/zero/1.0/) applies to the data made available in this article, unless otherwise stated in a credit line to the data. 
This study has evaluated the quality of life in patients at risk of diabetes and their behavior with some variables as sociodemographic, lifestyle, history, and established their difference in two territories of the Colombian Caribbean. The results of this study indicate that the HRQoL of people at risk of type 2 diabetes is affected by factors such as gender, city, dysglycemia, medication for hypertension and education level. Therefore, greater attention should be paid to these determinants of HRQL to design and implement strategies that reduce this risk of developing type 2 diabetes, prevent prediabetes and improve the quality of life in prediabetic or diabetic patients.

Keywords: Health related quality of life, Hyperglycemia, Type 2 diabetes, Risk factors

\section{Introduction}

It is estimated that 463 million adults around the world have diabetes and 374 million have prediabetes. It is expected that by 2045 the numbers of adults with diabetes and prediabetes will be 700 and 548 million, respectively. In Colombia, the prevalence of diabetes in the adult population is $8.4 \%$ and it is estimated that more than one million have undiagnosed diabetes $[1,2]$. Randomized clinical trials have shown the potential to prevent or delay the development of type 2 diabetes (T2D) in people at risk of developing the disease through lifestyle changes that included changes in eating habits and physical activity [3-5]. However, the first step in preventing diabetes is identifying people at risk while they are still in a normoglycemic state [6].

The measurement of blood glucose levels is the method commonly used for the identification of subjects at risk of diabetes, however, it is an invasive, time-consuming and expensive process, therefore, it is currently available of the diabetes risk score (FINDRISC) which allows identifying people with future risk of T2D [6, 7]. The FINDRISC scoring system was developed in Finland and is an instrument that has been adapted and validated in many countries including ours. In Colombia, a FINDRISC score $\geq 12$ is considered diabetes risk [8,9].

Several studies have established that T2D significantly reduces the health-related quality of life (HRQoL) [1014]. However, there is little and controversial literature on HRQoL in patients at risk for T2D [15-19]. Previous studies describing HRQoL in persons at risk for diabetes only included participants with impaired glucose tolerance or prediabetes [15-19]. However, these studies did not include people at future risk of developing T2D that may still have normal glucose levels [6].

HRQoL is the measure most frequently used to evaluate the impact of chronic illness or its treatment. The use of generic questionnaires such as the EQ-5D [20-24], SF-36 [25], and Health Utilities Index [26] have become the most common methods to establish the effects in terms of HRQoL. In the recent scientific literature, the EQ-5D tends to be the most widely used instrument in cost-utility analyses [27], not only because it is a short and cognitively simple questionnaire to complete but also because it is the instrument preferred by evaluation agencies of health technologies to establish measures of HRQoL in adults $[28,29]$. To our knowledge, there is no information available on HRQL in a population at risk of T2D through FINDRISC in Latin America. The objective of this study was to describe the characteristics of healthrelated quality of life (HRQoL) in a population at risk of developing type 2 diabetes in Barranquilla and Bogotá, Colombia.

\section{Materials and methods \\ Study design and population}

This cross-sectional study used baseline information collected within the PREDICOL project (Evaluation of a community health program for the prevention of type 2 diabetes and other cardio-metabolic risk factors in adults) developed in neighborhoods of two Colombian cities. In Bogotá, the capital city of Colombia with the largest number of inhabitants $(7,743,955$ inhabitants approximately), located in the central region of the country at $2630 \mathrm{~m}$ above sea level with a climate that ranges between 5 and $19{ }^{\circ} \mathrm{C}$, the project It was developed in the Palermo Sur neighborhood located in the southeast of the capital, has 50,000 inhabitants and has approximately 23.5 ha of land, mostly mountainous terrain and Barranquilla, the fourth most populated city in the country with $1,274,250$ inhabitants $(2.5 \%$ of the total population of Colombia) located in the Colombian Caribbean region above sea level with an average temperature of $29^{\circ} \mathrm{C}$, was developed in the El Pueblo neighborhood, located in the south west of the city with 240,000 inhabitants with flat land [30].

The study participants were recruited in Bogota and Barranquilla by cluster sampling [30]. During January 2018 to December 2019 approximately 1350 households of lower socio-economic strata were visited. All persons older than 30 years-of-age in each household were asked to fill in the Finnish Diabetes Risk Score (FINDRISC). In total, the FINDRISC was applied to 3738 people over 30 years-of-age. Respondents with a FINDRISC $\geq 12$ points were invited to the health care centers of each location for an oral glucose tolerance test (OGTT), managing to establish the glycemic status of 1166 participants 
(55\% of the 2118 at risk of T2D). This study excluded people with known type 2 diabetes, cognitive disabilities, or pregnant women. Further, the records of the participants with missing data (31 records with some missing data$2.6 \%$ in the variables used in this analysis and in the FINDRISC, HRQoL and physical activity questionnaires were excluded. The final sample included 1135 participants with completed questionnaires and who met previously defined criteria. This study was registered at ClinicalTrials.gov under the identification number NCT03049839. The methodology of this study has been published previously in a recent publication [31].

\section{Non-invasive measurements}

Before the blood glucose measurements, the participants' HRQoL was assessed using the Spanish version of the generic EQ-5D-3L questionnaire from the EuroQol group. This questionnaire consists of two parts, the EQ-5D descriptive component and the visual analog scale (EQ-VAS) [20, 21]. The descriptive component contains five dimensions: Mobility (MO), Self-Care (SC), Usual Activities (UA), Pain/Discomfort (P/D), and Anxiety/Depression (A/D). Each dimension consists of three levels: No problems (1), moderate problems (2), and extreme or severe problems (3), which are self-reported by the participant according to their health state. Combination of the digits of all the dimensions generates a 5 -digit number that describes the health state of the participant, giving 243 possible states [20, 22]. For example, state 11111 indicates no problem in any of the five dimensions, whereas state 11122 indicates the following: No problems walking (1), no problems with personal care (1), no problems with daily activities (2), moderate pain or discomfort (2), and moderate anxiety or depression (1). Many countries have developed a set of values or rates for all possible health states of the EQ-5D-3L using many preference-based techniques, however, Colombia does not yet have a locally appropriate set of values as suggested by the EuroQol group [22-24].

The second part of the EQ-5D is the EQ-VAS which records self-rated health on a millimeter scale ranging from 0 (worst imaginable health) to 100 (best imaginable health). The participant had to mark the point on a vertical line that best reflects the assessment of their overall health state $[20,22]$. In this study, due to the absence of a locally appropriate set of values, the EQ-5D score was not calculated, therefore only the frequencies of the EQ$5 \mathrm{D}-3 \mathrm{~L}$ health states were described and the HRQoL of participants was evaluated using the EQ-VAS.

The risk of T2D was assessed using the FINDRISC, which consists of eight items: age, body mass index (BMI), waist circumference, self-report of physical activity of at least 30 min per day, daily consumption of fruits or vegetables, history of high blood glucose, and family history of T2D [6, 7]. The total risk score is a simple sum of the individual weights, with a minimum score of 0 and maximum of 26 . This questionnaire has been validated in various countries including Colombia, and a score of $\geq 12$ has been used to define at risk of future T2D [8, 9, 32, 33]. For determining the physical activity (PA) level, the short version of the International Physical Activity Questionnaire (IPAQ-SV) was used, comprising seven questions addressing the frequency, intensity, and duration of physical activity during the last 7 days [34-37]. Data were also collected through a socio-demographic questionnaire that included information on the marital status, occupation and educational level of the participants.

\section{Invasive measurements}

Participants scoring $\geq 12$ on the FINDRISC were invited to an oral glucose tolerance test according to recommendations of the World Health Organization (WHO) $[38,39]$. The test started after $12 \mathrm{~h}$ fasting, and the fasting and 2-h blood samples were obtained after oral ingestion of water solution with $75 \mathrm{~g}$ anhydrous glucose. The glucose tolerance status was classified according to the WHO criteria [38]. Individuals who had fasting plasma glucose (FPG) level $\geq 126 \mathrm{mg} / \mathrm{dl}$ or $2 \mathrm{~h}$ plasma glucose $(2 \mathrm{hPG}) \geq 200 \mathrm{mg} / \mathrm{dl}$ were classified as having Type 2 diabetes mellitus. Those with $2 \mathrm{hPG} \geq 140 \mathrm{mg} /$ dl but $<200 \mathrm{mg} / \mathrm{dl}$, and $\mathrm{FPG}<100 \mathrm{mg} / \mathrm{dl}$ were classified as having isolated IGT. Isolated IFG was defined as FPG $\geq 110$ but $<126 \mathrm{mg} / \mathrm{dl}$, and $2 \mathrm{hPG}<140 \mathrm{mg} / \mathrm{dl}$. People with $2 \mathrm{hPG} \geq 140 \mathrm{mg} / \mathrm{dl}$ but $<200 \mathrm{mg} / \mathrm{dl}$, and $\mathrm{FPG} \geq 110$ but $<126 \mathrm{mg} / \mathrm{dl}$ were defined as combined IGT and IFG. Abnormal glucose tolerance was defined as T2D, IGT or IFG. $[38,40]$.

\section{Ethical aspects}

This study followed the rules of good clinical practice and guidelines of the Declaration of Helsinki. It was approved by the ethics committee of the Universidad del Norte (report 141 of 28 April 2016). Each participant signed the informed consent before participating and could withdraw from the study at any time they preferred.

\section{Statistical analysis}

Categorical variables and frequency distributions by health state were expressed in absolute numbers and percentages with 95\% confidence intervals (95\% CI). Quantitative variables were summarized by means and standard deviations and the evaluation expressed on a visual analog scale (EQ-VAS), with the most frequent health states using density graphs. Normality of the variables was verified through Kolmogorov-Smirnov tests. The nonparametric $U$ tests of Mann-Whitney and 
Kruskal-Wallis were used to evaluate statistical differences between subgroups, and the chi-square test $\left(\mathrm{X}^{2}\right)$ for differences in proportions (homogeneity test). To establish factors associated with presenting problems in the quality-of-life dimensions of the EQ-5D-3L descriptive system, several binary logistic regression models were tested. In the logistic regression model, the dependent variable was each domain of the quality-of-life questionnaire, previously dichotomized into no problems (level 1) and with some problem (levels 2 and 3). To summarize the data, only independent variables that showed a significant association with the quality-of-life dimensions were reported. The results are presented according to sex, city, and age group. $p$-values $<0.05$ were considered statistically significant. Processing and analysis of the data were carried out using statistical software SPSS version 25 (SPSS; Chicago, IL, USA), with the density graphs constructed using $\mathrm{R}$ version 4.0.0.

\section{Results}

Table 1 presents the baseline characteristics of the study participants. The final study population included 1135 participants from two cities in Colombia (Barranquilla, $\mathrm{n}=587$; Bogotá D.C., $\mathrm{n}=548$ ). Of these, $54.6 \%$ were older than 54 years, and the majority were women (76.4\%). The percentage of participants with prediabetes was $16 \%(n=182)$, with more frequent occurrence in participants from Barranquilla. The proportion of hidden diabetes was $9 \%$, with statistical equality between cities. There was $87.7 \%$ of the population presenting overweight or obese. Most participants had a low educational level (no education or not finishing high school, 67.2\%). The proportion of participants with little physical activity was larger in Barranquilla (91.7\%). The percentages of current smokers and those who reported receiving treatment for hypertension were $7.8 \%$ and $38.5 \%$, respectively.

The percentages of study participants expressing problems in each dimension of the EQ-5D-3L description system are shown in Table 2. Altogether, 21.7\% reported mobility problems, $2.0 \%$ self-care, $15.1 \%$ daily activities, $60.8 \%$ pain/discomfort, and $30.8 \%$ anxiety/ depression. The most frequent changes were the presence of moderate pain or discomfort $(53.9 \%$; $95 \%$ CI $51.0-56.8$ ), followed by moderately anxiety or depression (26.5\%; 95\% CI 24.0-29.2) and some problems walking. Reports of moderate pain or discomfort were statistically more numerous among women, without differentiation between cities. The proportion of participants who reported being moderately anxious or depressed was significantly higher among women and residents of Bogotá D.C. The percentage of participants who had trouble walking was larger among residents of Bogotá.
Table 1 Baseline characteristics of population at risk of T2D in Barranquilla and Bogotá, Colombia in 2018

\begin{tabular}{|c|c|c|c|c|}
\hline \multirow[t]{2}{*}{ Variable } & \multirow{2}{*}{$\begin{array}{l}\text { Total } \\
1135(100)\end{array}$} & \multicolumn{3}{|l|}{ City } \\
\hline & & $\begin{array}{l}\text { Barranquilla } \\
587(51.7)\end{array}$ & $\begin{array}{l}\text { Bogota D.C } \\
548(48.3)\end{array}$ & $p$-value ${ }^{a}$ \\
\hline \multicolumn{5}{|l|}{ Gender } \\
\hline Male & $268(23.6)$ & $143(24.4)$ & $125(22.8)$ & \multirow[t]{2}{*}{0.539} \\
\hline Female & $867(76.4)$ & $444(75.6)$ & $423(77.2)$ & \\
\hline \multicolumn{5}{|c|}{ Age groups (years) } \\
\hline $30-44$ & $226(19.9)$ & $140(23.9)$ & $86(15.7)$ & \multirow[t]{4}{*}{$<0.001$} \\
\hline $45-54$ & $289(25.5)$ & $168(28.6)$ & $121(22.1)$ & \\
\hline $55-64$ & $338(29.8)$ & $164(27.9)$ & $174(31.8)$ & \\
\hline$>64$ & $282(24.8)$ & $115(19.6)$ & $167(30.5)$ & \\
\hline \multicolumn{5}{|l|}{ Education level } \\
\hline No schooling & $287(25.3)$ & $97(16.5)$ & $190(34.7)$ & \multirow[t]{4}{*}{$<0.001$} \\
\hline $\begin{array}{l}\text { Elementary } \\
\text { school }\end{array}$ & $475(41.9)$ & $247(42.1)$ & $228(41.7)$ & \\
\hline $\begin{array}{l}\text { Junior high } \\
\text { school }\end{array}$ & $247(21.8)$ & $161(27.4)$ & $86(15.7)$ & \\
\hline Higher & $125(11.0)$ & $82(14.0)$ & $43(7.9)$ & \\
\hline \multicolumn{5}{|l|}{ Physical activity } \\
\hline Low & $854(75.2)$ & $538(91.7)$ & $316(57.7)$ & \multirow[t]{3}{*}{$<0.001$} \\
\hline Moderate & $186(16.4)$ & $30(5.1)$ & $156(28.5)$ & \\
\hline High & $95(8.4)$ & $19(3.2)$ & $76(13.9)$ & \\
\hline \multicolumn{5}{|l|}{$B M I\left(\mathrm{~kg} / \mathrm{m}^{2}\right)$} \\
\hline Normal weight & $140(12.3)$ & $67(11.4)$ & $73(13.3)$ & \multirow[t]{3}{*}{0.006} \\
\hline Overweight & $467(41.1)$ & $220(37.5)$ & $247(45.1)$ & \\
\hline Obesity & $528(46.5)$ & $300(51.1)$ & $228(41.6)$ & \\
\hline \multicolumn{5}{|c|}{ Glucose classification } \\
\hline $\begin{array}{l}\text { IFG, IGT or } \\
\text { IFG + IGT }\end{array}$ & $182(16.0)$ & $110(18.7)$ & $72(13.1)$ & \multirow[t]{2}{*}{0.002} \\
\hline $\mathrm{T} 2 \mathrm{D}$ & $102(9.0)$ & $63(10.7)$ & $39(7.1)$ & \\
\hline \multicolumn{5}{|c|}{ Hypertension treatment } \\
\hline Yes & $437(38.5)$ & $226(38.5)$ & $211(38.5)$ & 0.999 \\
\hline \multicolumn{5}{|l|}{ Current smokers } \\
\hline Yes & $88(7.8)$ & $24(4.1)$ & $64(11.8)$ & $<0.001$ \\
\hline
\end{tabular}

a Homogeneity test $\left(\mathrm{X}^{2}\right) ; \mathrm{n}(\%)$. BMI, body mass index; IFG, impaired fasting glucose; IGT, impaired glucose tolerance; T2D, type 2 diabetes

Participants reported their health in 45 health states (SQoL). However, of the 243 possible, 81.1\% reported their current health in only seven SQoL. Table 3 shows the percentages of the most reported health states (SQoL) in this study. The percentages are also shown by sex and city. Most of the participants (69.4\%) reported some problem in the dimensions of the EQ-5D-3L questionnaire. The most reported health status was complete health (SQoL: 11111, 30.6\%; 95\% CI 28.0-33.3), The percentage of participants free of health complains was statistically significantly higher in men than in women (39\% vs $28 \%$ ), and those living in Barranquilla compared with participants in Bogota (40\% vs $20 \%$ ). The second 


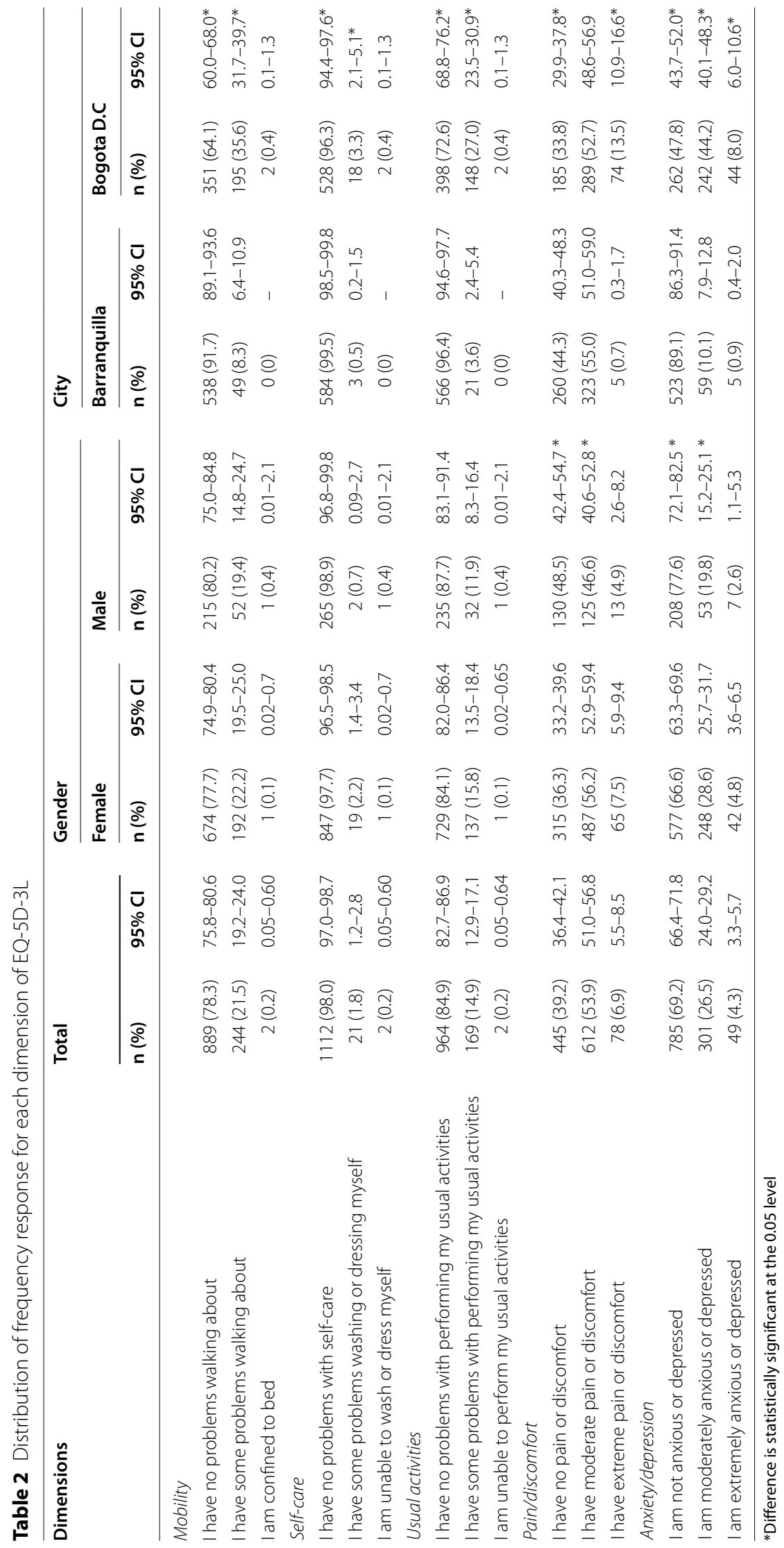


Table 3 Assessment of current health state for population at risk of T2D, by gender and city

\begin{tabular}{|c|c|c|c|c|c|c|c|c|c|c|}
\hline \multirow[t]{3}{*}{ SQoL } & \multirow{2}{*}{\multicolumn{2}{|c|}{$\begin{array}{l}\text { Total } \\
n=1135\end{array}$}} & \multicolumn{4}{|l|}{ Gender } & \multicolumn{4}{|l|}{ City } \\
\hline & & & \multicolumn{2}{|l|}{$\begin{array}{l}\text { Women } \\
n=867\end{array}$} & \multicolumn{2}{|l|}{$\begin{array}{l}\text { Men } \\
n=268\end{array}$} & \multicolumn{2}{|c|}{$\begin{array}{l}\text { Barranquilla } \\
n=587\end{array}$} & \multicolumn{2}{|c|}{$\begin{array}{l}\text { Bogota D.C. } \\
n=548\end{array}$} \\
\hline & n (\%) & $95 \% \mathrm{Cl}$ & n (\%) & $95 \% \mathrm{Cl}$ & n (\%) & $95 \% \mathrm{Cl}$ & n (\%) & $95 \% \mathrm{Cl}$ & n (\%) & $95 \% \mathrm{Cl}$ \\
\hline 11111 & 347 (30.6) & 28.0-33.3 & $243(28.0)$ & $25.1-31.1$ & $104(38.8)$ & $32.9-44.9^{*}$ & $237(40.4)$ & $36.5-44.4$ & $110(20.1)$ & $16.9-23.6^{*}$ \\
\hline 11121 & $306(27.0)$ & $24.5-29.6$ & $237(27.3)$ & $24.5-30.4$ & $69(25.8)$ & $20.6-31.4$ & $240(40.9)$ & $37.0-44.9$ & $66(12.0)$ & $9.6-15.0^{*}$ \\
\hline 11122 & $91(8.0)$ & $6.6-9.7$ & $79(9.1)$ & $7.4-11.2$ & $12(4.5)$ & $2.3-7.7^{*}$ & $31(5.3)$ & $3.8-7.4$ & $60(11.0)$ & $8.6-13.8^{*}$ \\
\hline 11112 & $57(5.0)$ & $3.9-6.5$ & $44(5.1)$ & $3.8-6.7$ & $13(4.9)$ & $2.6-8.2$ & $12(2.0)$ & $1.2-3.5$ & $45(8.2)$ & $6.2-10.8^{*}$ \\
\hline 21222 & $45(4.0)$ & $3.0-5.3$ & $35(4.0)$ & $2.9-5.6$ & $10(3.7)$ & $1.8-6.8$ & $3(0.5)$ & $0.2-1.5$ & $42(7.7)$ & $5.7-10.2^{*}$ \\
\hline 21121 & $42(3.7)$ & $2.8-5.0$ & $33(3.8)$ & $2.7-5.3$ & $9(3.4)$ & $1.6-6.3$ & $23(3.9)$ & $2.6-5.8$ & $19(3.5)$ & $2.2-5.4$ \\
\hline 21122 & $32(2.8)$ & $2.0-4.0$ & $26(3.0)$ & $2.1-4.4$ & $6(2.2)$ & $0.8-4.8$ & $7(1.2)$ & $0.6-2.4$ & $25(4.6)$ & $3.1-6.7^{*}$ \\
\hline 38 other states & 215 (18.9) & $16.8-21.3$ & 170 (19.6) & $17.1-22.4$ & $45(16.8)$ & $12.5-21.8$ & $34(5.8)$ & $4.2-8.0$ & $181(33.0)$ & $29.2-37.1^{*}$ \\
\hline
\end{tabular}

*Statistically significant difference $p$-value $<0.05$ (homogeneity test). 11111, without problems in all five dimensions; 11121, moderate pain/discomfort with no problems in the other four dimensions; 11122, moderate pain/discomfort and moderate anxiety/depression without problems in the other three dimensions; 11112 , moderate anxiety/depression without problems in the other four dimensions; 21222 , some trouble walking, no self-care problems, some trouble performing usual activities, moderate pain/discomfort, and moderate anxiety/depression; 21121, some walking problems and moderate pain/discomfort with no problems in the other three dimensions; 21122, some walking problems, moderate pain/discomfort and moderate anxiety/depression without problems in the other two dimensions

most reported health status was moderate pain or discomfort, with no problems in the other four dimensions (SQoL: 11121, 27\%; 95\% CI 24.5-29.6), with similarity by sex. However, a higher prevalence of moderate pain/ discomfort was found in participants in Barranquilla compared with those in Bogotá ( $p$-value $<0.05)$. Moderate pain / discomfort and moderate anxiety / depression with no problems in the other dimensions (SQoL: 11122) was presented $8 \%$ of the study participants. The SQoL: 11122 were more prevalent in women and those living in Bogotá compared to their counterparts. The percentage of those who presented some walking problems and moderate pain or discomfort without presenting problems in the other dimensions (SQoL: 21121) did not differ significantly by sex ( $3.8 \%$ vs $3.4 \%$ ) and by city ( $3.9 \%$ vs $3.5 \%)$. Approximately $10 \%(n=114)$ presented states with more severe alterations (three in any of the dimensions), a very large proportion compared to that found in the general Colombian population [41].

The scores obtained on the EQ-VAS for the seven most reported SQoLs show that the health state complete and states presenting moderate problems in one of the dimensions of quality of life had higher scores, in contrast to states presenting problems in more than one dimension (left part of Fig. 1). The average score for the complete health state was 79.3 \pm 17.1 (SQoL: 11111), and the corresponding value for women was smaller than for men ( $p$-value $<0.05)$. Similarly, women reported statistically significantly smaller values in SQoL 11121 compared to men. For SQoLs 11122, 21121, 21122 and 21222, no significant differences were detected, except in SQoL 21121 (some walking problems and moderate pain or discomfort, without problems in the other three dimensions), for which the average score was $53.3 \pm 18$ among men-statistically significantly smaller than the score for women $(73.2 \pm 12.9)$ (see right part of Fig. 1). Regarding living place, it was observed that the participants from Barranquilla (SQoL 11111) had lower values for their health state compared with those from Bogotá D.C., $78 \pm 16.7$ and $82.1 \pm 17.6$, respectively. For the other six SQoLs, no statistically significant differences were found in values determined by the EQ-VAS. The scores of people older than 55 were comparable to those of participants of younger age-groups even when they reported no health problems (Fig. 2).

Table 4 reveals the results of the logistic regression models for each dimension of the EQ-5D-3L, in which the city (OR 5.9; 95\% CI 4.2-8.4), age (OR 2.5; 95\% CI 1.8-3.5) and hypertension treatment (OR 1.6; 95\% CI 1.2-2.2) were statistically significant predictors of $\mathrm{MO}$. In addition, living place (OR 8.2; 95\% CI 2.4-27.9) and impaired glucose tolerance (OR 2.4; 95\% CI 1.04-5.8) were associated with SC. Moreover, living place, age, receipt of treatment for hypertension, and education were associated with UA. The problems in the dimension of P/D was greater among participants from Bogotá $(\mathrm{OR}=1.6$; 95\% CI 1.2-2.0) and women (OR 1.6; 95\% CI $1.2-2.2)$. The odds of $A / D$ was nine times higher in participants from Bogotá (OR 9.1, 95\% CI 6.6-12.4) compared with those from Barranquilla and almost twice as in women (OR 1.9, 95\% CI 1.3-2.7) than men.

\section{Discussion}

Our data indicate that gender, age, city, impaired glucose tolerance, treatment for hypertension, and educational level was associated with the HRQoL in people at risk of 

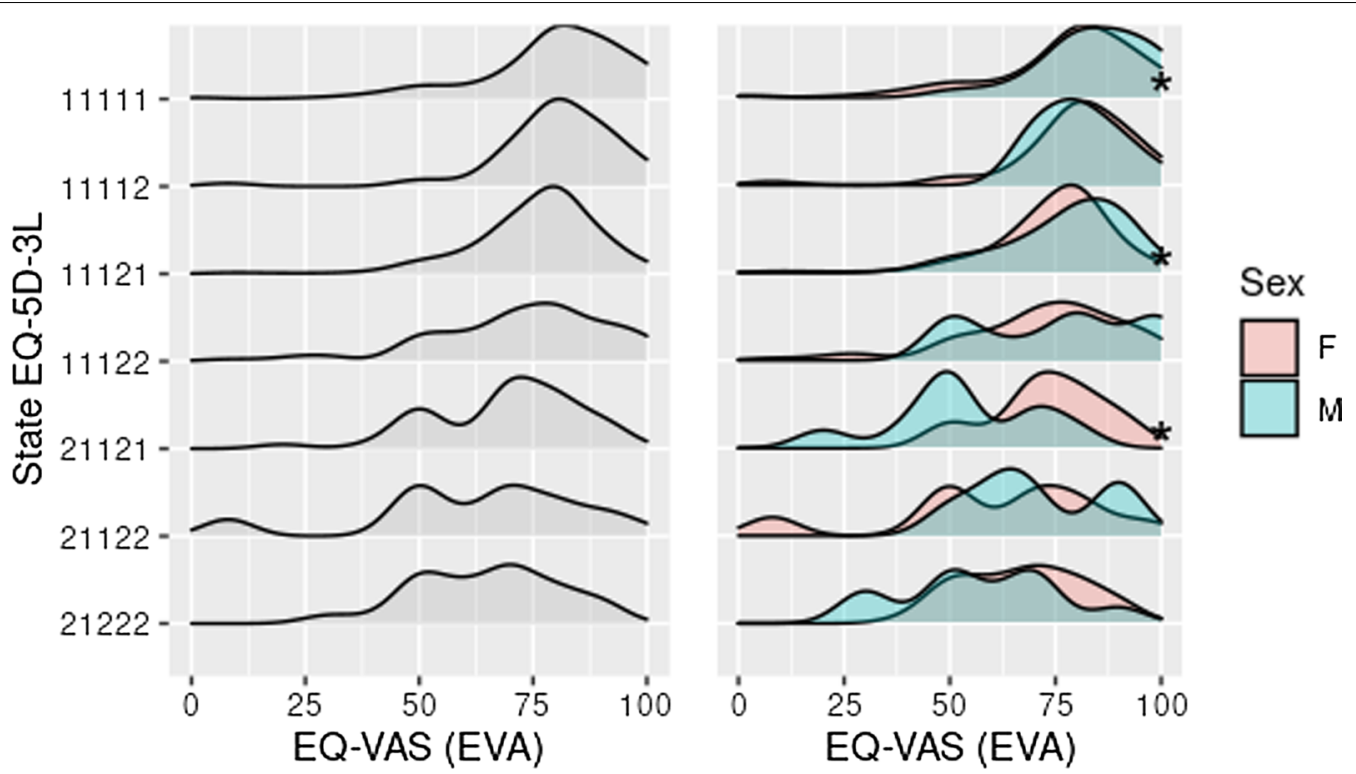

Fig. 1 Distribution of EQ-VAS score for most frequent health states in the population at risk of suffering T2D in Barranquilla and Bogotá, Colombia.

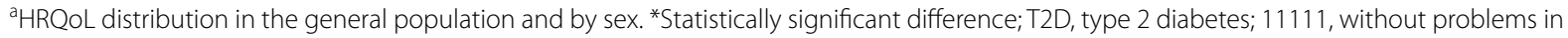
all five dimensions; 11121, moderate pain/discomfort with no problems in the other four dimensions; 11122, moderate pain/discomfort and moderate anxiety/depression without problems in the other three dimensions; 11112 , moderate anxiety/depression without problems in the other four dimensions; 21222, some trouble walking, no self-care problems, some trouble performing usual activities, moderate pain/discomfort, and moderate anxiety/depression; 21121, some walking problems and moderate pain/discomfort with no problems in the other three dimensions; 21122, some walking problems, moderate pain/discomfort and moderate anxiety/depression, without problems in the other two dimensions
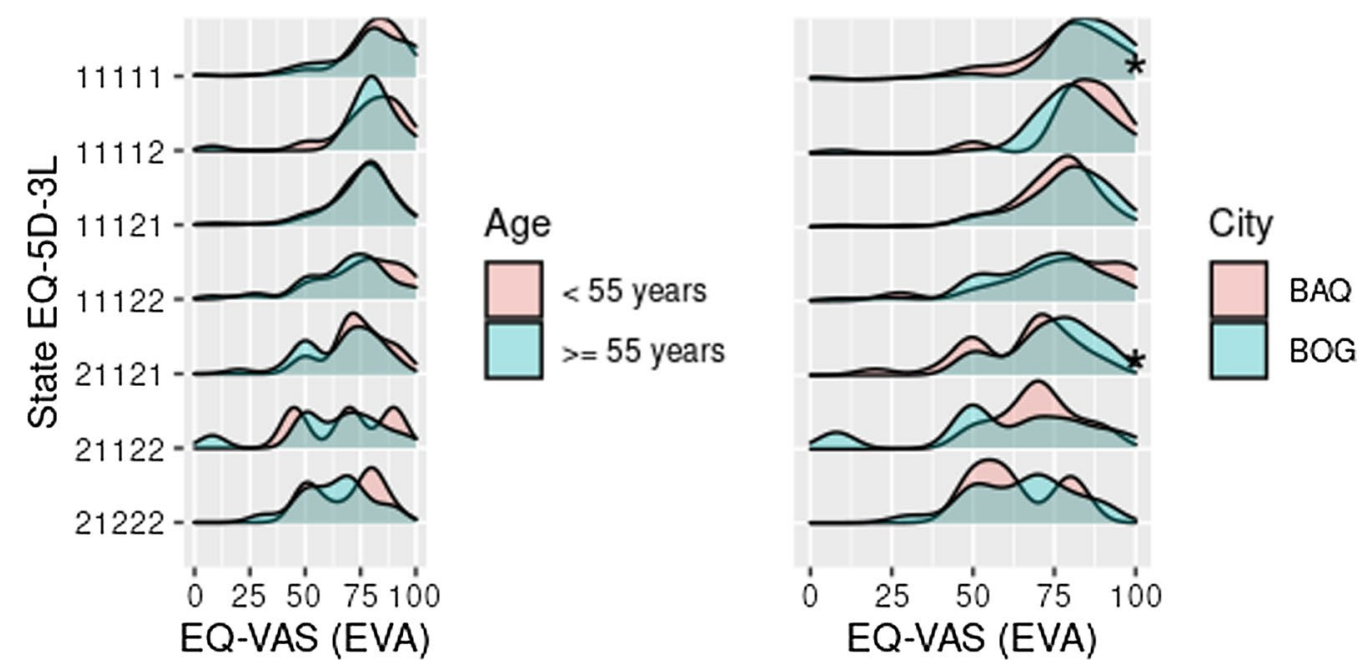

Fig. 2 Distribution of EQ-VAS score for the most frequent health states in the population at risk of T2D, according to city and age group. ${ }^{\text {a }} \mathrm{HRQOL}$ distribution according to age group and city; ${ }^{*}$ Statistically significant difference; T2D, type 2 diabetes; BAQ, Barranquilla; BOG, Bogotá; 11111 , without problems in all five dimensions; 11121, moderate pain/discomfort with no problems in the other four dimensions; 11122, moderate pain/ discomfort and moderate anxiety/depression without problems in the other three dimensions; 11112, moderate anxiety/depression without problems in the other four dimensions; 21222, some trouble walking, no self-care problems, some trouble performing usual activities, moderate pain/discomfort, and moderate anxiety/depression; 21121, some walking problems and moderate pain/discomfort with no problems in the other three dimensions; 21122 , some walking problems, moderate pain/discomfort and moderate anxiety/depression, with no problems in the other two dimensions 
Table 4 Factors associated with presenting problems in the of quality of life dimensions for the population at risk of T2D in Barranquilla and Bogota

\begin{tabular}{|c|c|c|c|c|c|}
\hline Dependent variable & Characteristic & B & SE & $p$-value & OR $(95 \% \mathrm{CI})$ \\
\hline \multirow[t]{9}{*}{ Mobility } & City & & & & \\
\hline & Barranquilla (Ref.) & & & & \\
\hline & Bogota D.C & 1.78 & 0.18 & $<0.001$ & $5.9(4.2-8.4)$ \\
\hline & Age group & & & & \\
\hline & $<55$ years (Ref.) & & & & \\
\hline & $\geq 55$ years & 0.91 & 0.18 & $<0.001$ & $2.5(1.8-3.5)$ \\
\hline & Hypertension treatment & & & & \\
\hline & No (Ref.) & & & & \\
\hline & Yes & 0.48 & 0.16 & 0.003 & $1.6(1.2-2.2)$ \\
\hline \multirow[t]{6}{*}{ Self-care } & City & & & & \\
\hline & Barranquilla (Ref.) & & & & \\
\hline & Bogota D.C & 2.1 & 0.63 & 0.001 & $8.2(2.4-27.9)$ \\
\hline & Glucose classification & & & & \\
\hline & Normal (Ref.) & & & & \\
\hline & Impaired glucose tolerance & 0.89 & 0.44 & 0.041 & $2.4(1.04-5.8)$ \\
\hline \multirow[t]{14}{*}{ Usual activities } & City & & & & \\
\hline & Barranquilla (Ref.) & & & & \\
\hline & Bogota D.C & 2.2 & 0.25 & $<0.001$ & $9.3(5.7-15.2)$ \\
\hline & Age group & & & & \\
\hline & $<55$ years (Ref.) & & & & \\
\hline & $\geq 55$ years & 0.78 & 0.22 & $<0.001$ & $2.2(1.4-3.3)$ \\
\hline & Hypertension treatment & & & & \\
\hline & No (Ref.) & & & & \\
\hline & Yes & 0.41 & 0.19 & 0.028 & $1.5(1.05-2.2)$ \\
\hline & Education level & & & & \\
\hline & Superior (Ref.) & & & & \\
\hline & No schooling & -0.373 & 0.34 & 0.265 & $0.69(0.36-1.3)$ \\
\hline & Elementary school & -0.671 & 0.32 & 0.039 & $0.51(0.27-0.97)$ \\
\hline & Junior high school & -0.979 & 0.39 & 0.011 & $0.38(0.18-0.8)$ \\
\hline \multirow[t]{6}{*}{ Pain/discomfort } & City & & & & \\
\hline & Barranquilla (Ref.) & & & & \\
\hline & Bogota D.C & 0.442 & 0.12 & $<0.001$ & $1.6(1.2-2.0)$ \\
\hline & Sex & & & & \\
\hline & Male (Ref.) & & & & \\
\hline & Female & 0.50 & 0.14 & $<0.001$ & $1.6(1.2-2.2)$ \\
\hline \multirow[t]{6}{*}{ Anxiety/depression } & City & & & & \\
\hline & Barranquilla (Ref.) & & & & \\
\hline & Bogota D.C & 2.2 & 0.16 & $<0.001$ & $9.1(6.6-12.4)$ \\
\hline & Sex & & & & \\
\hline & Male (Ref.) & & & & \\
\hline & Female & 0.63 & 0.18 & $<0.001$ & $1.9(1.3-2.7)$ \\
\hline
\end{tabular}

${ }^{\mathrm{a}}$ OR, Odds Ratio; Ref, reference group

Pain/Discomfort and Anxiety/Depression are the qualityof-life dimensions with the most reported problems in the population at risk of T2D, largely among female participants and residents of Bogotá (a large city). The most frequent alterations to the quality-of-life dimensions in this type of population were the presence of some type of pain or discomfort, followed by anxiety or depression and problems in walking.

To our knowledge, there have been no studies establishing HRQoL or reporting the most common alterations in 
the populations at risk of future diabetes using the EQ5D-3L in Colombia or South America. However, given that patients with prediabetes are at risk of progressing to the T2D and that many studies of patients with T2D used the EQ-5D questionnaire, we may draw some comparison with previous studies. Our data established that the dimension of quality of life with the greatest problem in patients at risk of developing T2D is Pain/Discomfort, which is in line with the current scientific evidence [15, 42,43 ] revealing that patients with prediabetes (IFG) presented greater problems in the dimensions of physical functioning and body pain, similar to that observed by Tapp et al. in patients with IGT. Moreover, a prospective study using three different HRQoL questionnaires (SF-36, SF-6D, and 15D) reported that the deterioration of glycemic status negatively impacts the physical dimensions of HRQoL [43]. However, Seppälä et al. reported that prediabetes was not associated with HRQoL [16]. Among studies that used the EQ-5D questionnaire for populations with $\mathrm{T} 2 \mathrm{D}$, the results coincide with ours [44-46]. The dimension with maximum reports of moderate or severe problems in patients with T2D was Pain/ Discomfort [44], consistent with the observations of Solli et al. [45] and Javanbakht et al. [46]. Recent studies of patients with diabetes confirmed that the most frequent alteration in the dimensions of quality of life was Pain/ Discomfort $[14,47]$.

Several studies in patients with T2D have reported that after the pain/discomfort dimension, the Anxiety/ Depression dimension was the second most reported problems [14, 45, 46]. However, in the population at risk of T2D, there is not enough scientific evidence to conclude that the presence of anxiety or depression is very prevalent among patients with prediabetes. However, it has been revealed that symptoms of depression were greater in women with prediabetes compared with participants with normal glucose metabolism [48]. A study in Greece using the 15D HRQoL questionnaire reported that patients with IGT presented problems in the dimension of "anguish" [19]. Finally, another study concluded that depression was more prevalent in people with T2D or at high risk of diabetes [49]. In our study, a large proportion of subjects at risk of T2D reported problems in the Mobility dimension, which is consistent with the results of Sakamaki et al. [44] and Makrilakis et al. [19].

The mean score on the visual analog scale (EQVAS) of the participants in our study was $74.3 \pm 17.3$. Unlike our study, previous research were all conducted in patients with T2D. For instance, a study of 1224 patients with diabetes, revealed a mean score of the EQVAS equivalent to $68 \pm 18.0$ [11], whereas in the study of Javanbakht et al., it was 56.8 (95\% CI 56.15-57.5) [43]. In other recent studies of patients with T2D, the mean score on the same scale was $65.22 \pm 9.32$ [14] and $80 \pm 12.9$ [47], respectively. According to these results, it may be asserted that the perception of quality of life of patients at risk of future diabetes is better than those who suffer from the disease. In the present analysis, the female participants, despite presenting the same health state as the men, yielded smaller values on the EQVAS in the generic quality of life questionnaire. Also, women with T2D were found to have a poorer quality of life than men $[11,14,44,46]$. Despite presenting the same complete health conditions as those from Bogotá, the participants from Barranquilla had lower values on the EQ-VAS. This agrees with the results of Rojas et al., who reported that citizens in the Atlantic region tended to express lower values compared to the other regions of Colombia [41]. Studies have shown that cities large countries present better living conditions due to economic development and the potentialization of the human condition that implies urban growth. However, several authors maintain, a city is large, promotes processes of spatial segregation and social exclusion, initiating the path to degradation of the quality of life of its inhabitants, since it is difficult to build a social fabric, a fundamental element of cooperation, solidarity and equity of a society important in the social determinants of the Health; evidencing that the geopolitical distribution of cities presents inequalities in all areas essentials of life that mark a diminished perception of the quality of life of the inhabitants [50,51].

According to Javanbakht et al. [46], people living in larger cities are more likely to report problems in the self-care dimension. Moreover, place of residence was statistically significantly associated with the dimensions of Self-Care Usual Activities, and Anxiety/Depression in 300 patients with T2D in Birjand/Iran [14]. Sex was associated with the Pain/Discomfort and Anxiety/ Depression dimensions, so women were more likely to report greater problems in these dimensions than men. This is agrees with findings in patients with T2D [11, 14, 46]. Alterations in the dimensions of Mobility and Usual Activities were more frequently reported by older participants (55 years or more) as in other studies as well $[14,46,52]$. These findings may be important for clinical practice because the use of HRQoL measures to evaluate the health, satisfaction and well-being results of the patient, provide an tool in the quality of patient care and in the decision-making process. Therefore, knowing the perception of quality of life (EQ-VAS), identifying factors related to HRQoL and having population scales are essential to characterize and interpret aspects of interest in persons at risk of diabetes [53, 54]. We encourage further inquiry into the HRQL of people at risk of diabetes, although we work with participants from lower 
socioeconomic strata, we recommend extending it to the rest of the socioeconomic strata.

Naturally, our study has some limitations. First, a set of values for the EQ-5D-3L in Colombia has not yet been established. Therefore, we were unable to report here the EQ-5D score or utility weights of the population at risk of diabetes (We hope to estimate the EQ-5D score using the set of values recommended for Colombia in future studies), and we were also unable to show the association or significant differences between the EQ-5D and EQ-VAS scores $[9,41]$. The low sensitivity and ceiling effect of the EQ-5D-3L compared to the 5-level version (EQ-5D-5L) places another limitation on the responses of the participants [21-24]. However, we prefer to use the 3-level version because this study is part of the health economics research to investigate the cost effectiveness of diabetes prevention programs and the guidelines for economic evaluation in Colombia recommend using the system EQ-5D-3L [55]. Furthermore, all the participants in our study belong to the lowest socioeconomic level. Therefore, our results do not allow us to generalize populations with different socioeconomic levels or are not necessarily applicable to the general population. We also lacked information on potentially useful clinical variables such as comorbidities and current treatments of the patients, which could behave as a confounding factor or have effects on the HRQL found in this study. Finally, as it is a cross-sectional study, the observed associations are not necessarily causal.

\section{Conclusions}

As sex, age, living place, impaired glucose tolerance, treatment for hypertension, and educational level were predictors of HRQoL in people at future risk of T2D, greater attention should be paid to these determinants in order to design, reorient and implement strategies that to achieve better health outcomes. Due to the characteristics related to this study, studies are required in populations of other socioeconomic strata that allow extrapolating the results to the entire population at risk of diabetes and identifying aspects of interest in this population. Nevertheless, future studies should focus on validating utility values in this type of population, estimating HRQoL according to glycemic status and determining if self-reported perceptions are consistent with the level of utility of the participants.

\section{Acknowledgements}

Not applicable.

\section{Disclaimer}

The authors alone are responsible for the views expressed in this publication and they do not necessarily represent the views, decisions, or policies of the institutions with which they are affiliated.
Authors' contributions

$L A, P A, T A, R T, K F, S R$ and NB contributed conception and design of the study. TA, PA, RT and LA supervised data collection. LA organized the dataset. KF, TA, $L A$ and PA performed the statistical analysis. TA, RT, KF, and LA wrote the first draft of the manuscript with support from PA, JN, NB and SDR. All authors contributed to manuscript revision, read and approved the submitted version.

\section{Funding}

This project was financed by the Colombian National Program for Science, Technology, and Health Innovation (COLCIENCIAS) in line with the theme focused on chronic non-transmutable diseases. This was in response to the 744 Call for projects in science, technology, and health innovation of 2016 in association with the Universidad del Norte of Barranquilla and the Colombian Diabetes Association.

\section{Availability of data and material}

The datasets presented in this article are not readily available because The PREDICOL Project is a Project that is currently in progress, therefore the database according to the regulations may not be published until the end of the study, for any requirement you can contact the authors. Requests to access the datasets should be directed to laanillo@uninorte.edu.co. All authors certify that they have no affiliations with or involvement in any organization or entity with any financial interest or non-financial interest in the subject matter or materials discussed in this manuscript.

\section{Declarations}

\section{Ethics approval}

This study was performed in line with the principles of the Declaration of Helsinki. The studies involving human participants were reviewed and approved by ethics committee of the Universidad del Norte, Barranquilla, Colombia.

\section{Consent to participate}

The patients/participants provided their written informed consent to participate in this study.

\section{Code availability}

Not applicable.

\section{Competing interests}

The authors declare that they have no competing interests.

\section{Author details}

${ }^{1}$ Department of Mathematics and Statistics, Division of Basic Sciences, Universidad del Norte, Barranquilla, Colombia. ${ }^{2}$ Department of Public Health, Division of Health Sciences, Universidad del Norte, Barranquilla, Colombia. ${ }^{3}$ Department of Interdisciplinary Research, University Center CIFE, Cuernavacas-MoreIos, Mexico. ${ }^{4}$ Department of Economics, Division of Humanities and Sciences Division Social, Universidad del Norte, Barranquilla, Colombia. ${ }^{5}$ Asociación Colombiana de Diabetes, Bogotá, Colombia. . Javeriana University, Bogotá, Colombia. ${ }^{7}$ San Ignacio University Hospital, Bogotá, Colombia. ${ }^{8}$ Department of International Health, National School of Public Health, Instituto de Salud Carlos III, Madrid, Spain. ${ }^{9}$ World Community for Prevention of Diabetes (WCPD) Foundation, Madrid, Spain. ${ }^{10}$ Department of Translational Medicine, Herbert Wertheim College of Medicine, Florida International University, Miami, FL, USA.

${ }^{11}$ Department of Public Health, Faculty of Medicine, University of Helsinki, Helsinki, Finland. ${ }^{12}$ Department of Health Policy and Management, Robert Stempel College of Public Health and Social Work, Florida International University, Miami, FL, USA.

Received: 3 June 2021 Accepted: 16 November 2021

Published online: 20 December 2021

\section{References}

1. Noncommunicable diseases. Global Action Plan for the Prevention and Control of NCDs 2013-2020. Who.int. World Health Organization; 2013 [cited 3 June 2021]. http://www.who.int/nmh/events/ncd_action_plan/ en/. 
2. IDF Diabetes Atlas 9th edition 2019. Diabetesatlas.org. [cited 3 June 2021]. https://www.diabetesatlas.org.

3. Cefalu WT, Buse JB, Tuomilehto J, Fleming GA, Ferrannini E, Gerstein HC, et al. Update and next steps for real-world translation of interventions for type 2 diabetes prevention: reflections from a diabetes care editors' expert forum. Diabetes Care. 2016;39(7):1186-201. https://doi.org/10. 2337/dc16-0873.

4. Tuomilehto J, Lindström J, Eriksson JG, Valle TT, Hämäläinen H, IlanneParikka P, et al. Prevention of type 2 diabetes mellitus by changes in lifestyle among subjects with impaired glucose tolerance. N Engl I Med. 2001;344(18):1343-50. https://doi.org/10.1056/NEJM200105033441801.

5. Knowler WC, Barrett-Connor E, Fowler SE, Hamman RF, Lachin JM, Walker EA, et al. Reduction in the incidence of type 2 diabetes with lifestyle intervention or metformin. N Engl J Med. 2002;346(6):393-403. https:// doi.org/10.1056/NEJMoa012512.

6. Lindström J, Tuomilehto J. The diabetes risk score: a practical tool to predict type 2 diabetes risk. Diabetes Care. 2003;26(3):725-31. https://doi. org/10.2337/diacare.26.3.725.

7. Saaristo T, Peltonen M, Lindström J, Saarikoski L, Sundvall J, Eriksson JG, et al. Cross-sectional evaluation of the Finnish Diabetes Risk Score: a too to identify undetected type 2 diabetes, abnormal glucose tolerance and metabolic syndrome. Diab Vasc Dis Res. 2005;2(2):67-72. https://doi.org/ 10.3132/dvdr.2005.011.

8. Franciosi M, De Berardis G, Rossi MCE, Sacco M, Belfiglio M, Pellegrini F, et al. Use of the diabetes risk score for opportunistic screening of undiagnosed diabetes and impaired glucose tolerance: the IGLOO (Impaired Glucose Tolerance and Long-Term Outcomes Observational) study. Diabetes Care. 2005;28(5):1 187-94. https://doi.org/10.2337/diacare.28.5 1187

9. Gomez-Arbelaez D, Alvarado-Jurado L, Ayala-Castillo M, Forero-Naranjo L, Camacho PA, Lopez-Jaramillo P. Evaluation of the Finnish Diabetes Risk Score to predict type 2 diabetes mellitus in a Colombian population: a longitudinal observational study. World J Diabetes. 2015;6(17):1337-44. https://doi.org/10.4239/wjd.v6.i17.1337.

10. Clouet F, Excler-Cavailher G, Christophe B, Masson F, Fasquel D. Type 2 diabetes and short form 36-items Health Survey. Diabetes Metab. 2001;27(6):711-7.

11. Redekop WK, Koopmanschap MA, Stolk RP, Rutten GEHM, Wolffenbuttel BHR, Niessen LW. Health-related quality of life and treatment satisfaction in Dutch patients with type 2 diabetes. Diabetes Care. 2002;25(3):458-63. https://doi.org/10.2337/diacare.25.3.458.

12. Schunk M, Reitmeir P, Schipf S, Völzke H, Meisinger C, Thorand B, et al. Health-related quality of life in subjects with and without Type 2 diabetes: pooled analysis of five population-based surveys in Germany: healthrelated quality of life in subjects with and without Type 2 diabetes. Diabetes Med. 2012;29(5):646-53. https://doi.org/10.1111/j.1464-5491. 2011.03465.x

13. Trikkalinou A, Papazafiropoulou AK, Melidonis A. Type 2 diabetes and quality of life. World J Diabetes. 2017;8(4):120-9. https://doi.org/10.4239/ wjd.v8.14.120.

14. Abedini MR, Bijari B, Miri Z, Shakhs Emampour F, Abbasi A. The quality of life of the patients with diabetes type 2 using EQ-5D- 5 L in Birjand. Health Qual Life Outcomes. 2020;18(1):18. https://doi.org/10.1186/ s12955-020-1277-8.

15. Chittleborough CR, Baldock KL, Taylor AW, Phillips PJ, North West Adelaide Health Study Team. Health status assessed by the SF-36 along the diabetes continuum in an Australian population. Qual Life Res. 2006;15(4):68794. https://doi.org/10.1007/s11136-005-3570-8.

16. Seppälä T, Saxen U, Kautiainen H, Järvenpää S, Korhonen PE. Impaired glucose metabolism and health related quality of life. Prim Care Diabetes. 2013;7(3):223-7. https://doi.org/10.1016/j.pcd.2013.03.001.

17. Hunger M, Holle R, Meisinger C, Rathmann W, Peters A, Schunk M. Longitudinal changes in health-related quality of life in normal glucose tolerance, prediabetes and type 2 diabetes: results from the KORA S4/F4 cohort study. Qual Life Res. 2014;23(9):2515-20. https://doi.org/10.1007/ s11136-014-0689-5.

18. Neumann A, Schoffer O, Norström F, Norberg M, Klug SJ, Lindholm L. Health-related quality of life for pre-diabetic states and type 2 diabetes mellitus: a cross-sectional study in Västerbotten Sweden. Health Qual Life Outcomes. 2014;12(1):150. https://doi.org/10.1186/s12955-014-0150-z.
19. Makrilakis K, Liatis S, Tsiakou A, Stathi C, Papachristoforou E, Perrea D, et al. Comparison of health-related quality of Life (HRQOL) among patients with pre-diabetes, diabetes and normal glucose tolerance, using the 15D-HRQOL questionnaire in Greece: the DEPLAN study. BMC Endocr Disord. 2018;18(1):1-10. https://doi.org/10.1186/s12902-018-0261-3.

20. EuroQol Group. EuroQol—a new facility for the measurement of healthrelated quality of life. Health Policy (Amst, Neth). 1990;16(3):199-208. https://doi.org/10.1016/0168-8510(90)90421-9.

21. Herdman M, Badia X, Berra S. El EuroQol-5D: una alternativa sencilla para la medición de la calidad de vida relacionada con la salud en atención primaria. Aten Primaria. 2001;28(6):425-9. https://doi.org/10.1016/S02126567(01)70406-4.

22. EQ-5D-3L-EQ-5D. Euroqol.org. [cited 3 June 2021]. https://euroqol.org/ eq-5d-instruments/eq-5d-3l-about/.

23. Dolan P. Modeling valuations for EuroQol health states. Med Care. 1997;35(11):1095-108. https://doi.org/10.1097/00005650-19971 1000-00002.

24. Shaw JW, Johnson JA, Coons SJ. US valuation of the EQ-5D health states: development and testing of the D1 valuation model. Med Care. 2005:43:203-20. https://doi.org/10.1097/00005650-200503000-00003.

25. McHorney CA, Ware JE Jr, Rachel Lu JF, Sherbourne CD. The MOS 36-Item short-form health survey (SF-36): III. Tests of data quality, scaling assumptions, and reliability across diverse patient groups. Med Care. 1994;32(1):40-66. https://doi.org/10.1097/00005650-199401000-00004.

26. Horsman J, Furlong W, Feeny D, Torrance G. The Health Utilities Index (HUI): concepts, measurement properties and applications. Health Qual Life Outcomes. 2003;1 (1):54. https://doi.org/10.1186/1477-7525-1-54.

27. Richardson G, Manca A. Calculation of quality adjusted life years in the published literature: a review of methodology and transparency. Health Econ. 2004;13(12):1203-10. https://doi.org/10.1002/hec.901.

28. NICE [National Institute for Health and Care Excellence]. Guide to the methods of technology appraisal. (2013, April 2004). [cited 3 June 2021]. https://assets.publishing.service.gov.uk/government/uploads/system/ uploads/attachment_data/file/191504/NICE_guide_to_the_methods_ of_technology_appraisal.pdf.

29. Methods for the economic evaluation of health care programmesresearch database, the University of York. York.ac.uk. [cited 3 June 2021]. https://pure.york.ac.uk/portal/en/publications/methods-for-the-econo mic-evaluation-of-health-care-programmes(8f69bcee-cdac-44fa-871 cf821470df60a)/export.html

30. DANE. Proyecciones de Población 2018-2020 Total municipal por área. Retrieved 30 June 2020

31. Acosta T, Tuesca R, Florez K, Barengo NC, Anillo L, Flórez-García V, Acosta J, Carvajal L, de la Rosa S, Pachón MJ, Aschner P. Factors associated with low physical activity in two latin american populations at risk of developing type 2 diabetes: an exploratory analysis. Front Public Health. 2021;8:1035. https://doi.org/10.3389/fpubh.2020.589484.

32. Makrilakis K, Liatis S, Grammatikou S, Perrea D, Stathi C, Tsiligros P, et al. Validation of the Finnish diabetes risk score (FINDRISC) questionnaire for screening for undiagnosed type 2 diabetes, dysglycaemia and the metabolic syndrome in Greece. Diabetes Metab. 2011;37(2):144-51. https:// doi.org/10.1016/j.diabet.2010.09.006.

33. Aschner P, Nieto-Martínez R, Marin A, Ríos M. Validation of the FINDRISK score as a screening tool for people with impaired glucose regulation in Latin America using modified score points for waist circumference according to the validate regional cutoff values for abdominal obesity. Minerva Endocrinol. 2012;37.

34. Pardini R, Matsudo S. Validation of the International Physical Activity Questionnaire (IPAQ version 6): pilot study in Brazilian young adults. Rev Bras Cien Exerc. 2001;9:45-51.

35. Craig CL, Marshall AL, Sjöström M, Bauman AE, Booth ML, Ainsworth BE, et al. International physical activity questionnaire: 12-country reliability and validity. Med Sci Sports Exerc. 2003;35(8):1381-95. https://doi.org/10. 1249/01.MSS.0000078924.61453.FB.

36. Brown WJ, Trost SG, Bauman A, Mummery K, Owen N. Test-retest reliability of four physical activity measures used in population surveys. J Sci Med Sport. 2004;7(2):205-15. https://doi.org/10.1016/S1440-2440(04) 80010-0.

37. Ekelund U, Sepp H, Brage S, Becker W, Jakes R, Hennings M, et al. Criterion-related validity of the last 7-day, short form of the International 
Physical Activity Questionnaire in Swedish adults. Public Health Nutr. 2006;9(2):258-65. https://doi.org/10.1079/PHN2005840.

38. World Health Organization. Definition, diagnosis and classification of diabetes mellitus and its complications: report of a WHO consultation. Part 1, Diagnosis and classification of diabetes mellitus. Geneva: World Health Organization; 1999.

39. World Health Organization. Definition and Diagnosis of Diabetes Mellitus and Intermediate Hyperglycemia. 2006. Accessed 20 May 2020. https:// www.who.int/diabetes/publications/diagnosis_diabetes2006/en/.

40. WHO / Use of glycated haemoglobin (HbA1c) in the diagnosis of diabetes mellitus. 2013 [cited 3 June 2021]. https://www.who.int/diabetes/publi cations/diagnosis_diabetes2011/en/.

41. Rojas-Reyes MX, Gomez-Restrepo C, Rodríguez VA, Dennis-Verano R, Kind P. Calidad de vida relacionada con salud en la población Colombiana: ¿Cómo valoran los colombianos su estado de salud? Rev Salud Publica (Bogota). 2017;9(3):340-6. https://doi.org/10.15446/rsap.v19n3.54226.

42. Tapp RJ, Dunstan DW, Phillips P, Tonkin A, Zimmet PZ, Shaw JE, et al. Association between impaired glucose metabolism and quality of life: results from the Australian diabetes obesity and lifestyle study. Diabetes Res Clin Pract. 2006;74(2):154-61. https://doi.org/10.1016/j.diabres.2006.03.012.

43. Väätäinen S, Keinänen-Kiukaanniemi S, Saramies J, Uusitalo H, Tuomilehto J, Martikainen J. Quality of life along the diabetes continuum: a crosssectional view of health-related quality of life and general health status in middle-aged and older Finns. Qual Life Res. 2014;23(7):1935-44. https:// doi.org/10.1007/s11136-014-0638-3.

44. Sakamaki H, Ikeda S, Ikegami N, Uchigata Y, Iwamoto Y, Origasa H, et al. Measurement of HRQL using EQ-5D in patients with type 2 diabetes mellitus in Japan. Value Health. 2006;9(1):47-53. https://doi.org/10.1111/j. 1524-4733.2006.00080.x.

45. Solli O, Stavem K, Kristiansen IS. Health-related quality of life in diabetes: the associations of complications with EQ-5D scores. Health Qual Life Outcomes. 2010;8(1):18. https://doi.org/10.1186/1477-7525-8-18.

46. Javanbakht M, Abolhasani F, Mashayekhi A, Baradaran HR, Jahangiri noudeh Y. Health related quality of life in patients with type 2 diabetes mellitus in Iran: a national survey. PLoS ONE. 2012;7(8):e44526. https://doi. org/10.1371/journal.pone.0044526.

47. Sholihat NK, Utami W. Health-related quality of life among patients undergoing chronic disease management: a cross-sectional study. J Appl Pharm Sci. 2020;10(3):75-9.

48. Adriaanse MC, Dekker JM, Heine RJ, Snoek FJ, Beekman AJ, Stehouwer $C D$, et al. Symptoms of depression in people with impaired glucose metabolism or Type 2 diabetes mellitus: The Hoorn Study. Diabet Med. 2008;25(7):843-9. https://doi.org/10.1111/j.1464-5491.2008.02464.x.

49. Grandy S, Chapman RH, Fox KM, SHIELD Study Group. Quality of life and depression of people living with type 2 diabetes mellitus and those at low and high risk for type 2 diabetes: findings from the Study to Help Improve Early evaluation and management of risk factors Leading to Diabetes (SHIELD): HRQoL with or at risk for type 2 diabetes. Int J Clin Pract. 2008;62(4):562-8. https://doi.org/10.1111/j.1742-1241.2008.01703.x.

50. Chaparro F, Ortiz F, Bruges M, Cuervo N, Bustamante D. Formulation of a knowledge region city strategy for Bogotá. A proposal for action. Bogotá: Universidad del Rosario - District Planning Administrative Department (DAPD). 2006; 16734481. (s. f.). https://issuu.com/publicacionesfaciso/ docs/revista_estudios_sociales_n_49.

51. Durán RAV, Palacio LMA, Sañudo JEP, Solano MR. Human development and quality of life integrated in an Urban Management Model for Barranquilla. 2009. https://www.academia.edu/3363982/El_desarrollo_ humano_y_la_calidad_de_vida_integrados_en_un_Modelo_de_Gesti\% C3\%B3n_Urbana_para_Barranquilla_Colombia_Human_development_ and_quality_of_life_integrated_in_an_urban_management_model_for_ Barranquilla_Colombia_.

52. Lee WJ, Song K-H, Noh JH, Choi YJ, Jo M-W. Health-related quality of life using the EuroQol 5D questionnaire in Korean patients with type 2 diabetes. J Korean Med Sci. 2012;27(3):255-60. https://doi.org/10.3346/ jkms.2012.27.3.255.

53. Ruiz MA, Pardo A. Calidad de vida relacionada con la salud: definición y utilización en la práctica médica. Pharmacoecon Span Res Artic. 2005;2:31-43. https://doi.org/10.1007/BF03320897.

54. Urzúa MA, Chirino A, Valladares G. Health related quality of life among patients with type 2 diabetes mellitus. Rev Méd Chile. 2011;139(3):31320. https://doi.org/10.4067/S0034-98872011000300005.
55. IETS [Instituto de Evaluación Tecnológica en Salud]. Guidelines for the economic evaluation of healthcare technologies in Colombia: technical support documents. 2014.

\section{Publisher's Note}

Springer Nature remains neutral with regard to jurisdictional claims in published maps and institutional affiliations.
Ready to submit your research? Choose BMC and benefit from:

- fast, convenient online submission

- thorough peer review by experienced researchers in your field

- rapid publication on acceptance

- support for research data, including large and complex data types

- gold Open Access which fosters wider collaboration and increased citations

- maximum visibility for your research: over 100M website views per year

At BMC, research is always in progress.

Learn more biomedcentral.com/submissions 